\title{
4
}

\section{Underpinning Development: Health and Health Workforce in Northern Australia}

Scott R. Davis, Felicity Croker and Alexandra Edelman

The renewed focus on the economic potential of Northern Australia recognises its unique proximity to Asia and the Indo-Pacific region and its strategic position within the fastest growing global zone, the tropics (Commonwealth of Australia, 2012; State of the Tropics, 2014, 2017). Northern Australia is recognised as vital to Australia's future economic development over the next 30 years of the Asia-Pacific century (Australian Government, 2015; Commonwealth of Australia, 2012; Hill, 2013; State of the Tropics, 2014). With sustained policy and political commitment, Northern Australia has the capacity to be an international leader in providing health professional education, tropical health research and development, and innovative health service models that will enable development of a knowledge-based economic platform for the region (Australian Government, 2015; Edelman et al., 2018; Hill, 2013; Joint Select Committee on Northern Australia, 2014).

Achieving this vision requires recognising that the success of Northern Australia must be underpinned by a healthy and productive population. This population needs to be supported by a health system that can respond to significant demographic and epidemiological changes and transitions including population ageing, emerging tropical epidemics and the growing global prevalence of non-communicable diseases (WHO, 2016). Future-proofing Northern Australia's capacity within the tropics 
worldwide and throughout the Asia-Pacific century needs to be founded on a sustainable, adaptable, flexible health system with a workforce capable of responding to the dynamic opportunities and challenges ahead (ABS, 2018a; Commonwealth of Australia, 2012; Davis \& Vernon, 2014; Department of Jobs and Small Business, 2018; Hill, 2013; Liberal Party of Australia, 2013; State of the Tropics, 2014, 2017).

Developing appropriate long-term strategies to enable Northern Australia to achieve its potential requires a strengths-based approach that recognises the geographic, environmental and sociocultural challenges as foundational to a knowledge-based economy. Northern Australia has the potential to be a leader in health systems innovation and health workforce training in the tropics worldwide, leading to significant health, social, cultural and economic benefits to both Australia and its near neighbours (Davis \& Vernon, 2014; Edelman et al., 2018; Liberal Party of Australia, 2013). With appropriate policy and political support, this region can build on existing capacity and expertise in health, education and research sectors (ABS, 2018a; Australian Government, 2015; Commonwealth of Australia, 2012; Department of Jobs and Small Business, 2018; Hill, 2013; Mason, 2013; State of the Tropics, 2014).

This chapter outlines the critical health challenges facing Northern Australia, provides an overview of the raft of health and health workforce reforms that are leading to improved health outcomes, and makes recommendations for future actions based on key opportunities in the region.

\section{Northern Australia: The Context}

Health in Northern Australia ${ }^{1}$ reflects a combination of unique geographic and demographic factors. While the tropical cities of Cairns, Townsville and Darwin are uniquely positioned as thriving hubs servicing the region, the remainder of Northern Australia is classified as rural or remote, ${ }^{2}$

\footnotetext{
1 Northern Australia is defined as being above the Tropic of Capricorn by the Greater Northern Australia Regional Training Network (GNARTN) Council. This is consistent with the definition provided by the Joint Select Committee on Northern Australia (2014) and that used by the Australian Government (2015).

2 Based on the ABS Australian Standard Geographical Classification Remoteness Area classification, the term 'rural and remote' encompasses inner regional, outer regional, remote or very remote geographical areas. Increasingly, the Modified Monash Model (MMM) classifications are applied to categorise regionality and remoteness, with MMM 1-2 being metropolitan, MMM 3 being a large regional town and MMM 7 being a very remote community.
} 
representing approximately one-third of Australia's outer regional and remote population (Joint Select Committee on Northern Australia, 2014). Northern Australia's population of 1.3 million people is distributed unevenly across a vast geographic area, and only four out of the 74 Local Government Areas have populations of over 100,000 people. Northern Australia also encompasses around 29 per cent of the nation's Aboriginal and Torres Strait Islander population (ABS, 2017, 2018a, 2018b; Mason, 2013). Currently, 5.5 per cent of Australia's workers are spread across the north occupying around 646,000 jobs, predominantly in the health and social services and construction sectors (Australian Government, 2015; Department of Jobs and Small Business, 2018; WHO, 2016). There is the potential to diversify employment through developing a workforce with internationally recognised expertise in health professional education, medical research and health systems innovation and reform (HWA, 2013; NHWPRC, 2010).

People living in rural and remote parts of Australia are at risk of poorer health status, shorter lives, higher rates of accident and injury, greater levels of illness, and lower rates of certain medical treatments. Mortality and hospitalisation rates and prevalence of health risk factors generally increase, and access to health services becomes more limited, with increasing remoteness (ABS, 2017; AIHW, 2013, 2018; Australian Medical Workforce Advisory Committee, 1998; Davis \& Vernon, 2014; HWA, 2013; NHWPRC, 2010; Wakerman, 2004).

This is compounded for Indigenous Australians within the northern region. Indigenous Australians' health outcomes are significantly worse compared to either non-Indigenous Australians within the same region or other Indigenous Australians living in urban areas (AIHW, 2018; State of the Tropics, 2014). Health in Northern Australia also encompasses tropical, exotic and infectious disease, necessitating consideration of biosecurity, relationships with neighbouring countries and people movements across the northern border (Australian Government, 2015).

Multiple political, social, cultural and economic factors contribute to the health disadvantage experienced by people living in rural and remote communities, including population transience, high capital costs of infrastructure and a maldistributed workforce with recruitment and retention difficulties (NHWPRC, 2010; Australian Medical Workforce Advisory Committee, 1998; AIHW, 2013; Humphreys et al., 2006; Productivity Commission, 2005; Godwin et al., 2014; Insight Economics, 
2012; HWA, 2012). These factors are compounded by significant geographical challenges in delivering accessible, affordable and appropriate health care services to low population densities, in small settlements and across large distances. Not all the trends are negative-Australians living in rural areas generally have higher levels of social cohesiveness, including higher rates of participation in volunteer work and feelings of safety in their community (AIHW, 2018).

Health care in Northern Australia has evolved unique characteristics and strengths, including a transdisciplinary practice environment requiring generalist (rather than specialist) skills and training. Health practitioners working in remote areas work in a cross-cultural context; serve small, dispersed and often highly mobile populations; operate in a physical environment of climatic extremes; and contend with geographical, professional and often social isolation (HWA, 2012, 2013; Insight Economics, 2012; NHWPRC; 2010). Many of these characteristics present unique challenges for health service providers and policymakers, with the following being highlighted in the Productivity Commission's (2005) report on Australia's health workforce:

- limited access to supporting health professionals, facilities and locum services

- less availability of continuing professional development

- lower housing standards

- more restricted education and employment opportunities for other family members.

One of the most pressing and persistent health challenges in Northern Australia is the geographic maldistribution of health professionals, meaning shortages in rural and remote areas. The Review of Australian Government Health Workforce Programs ('Mason Review') (Mason, 2013) identified maldistribution as the most significant health workforce issue, finding 'inadequate or non-existent service provision' in rural, remote and Indigenous communities (p. 6), populations of extreme disadvantage and some outer metropolitan communities coexisting with oversupply in other areas for some health professions (Davis \& Vernon, 2014). The undesirable outcomes of workforce shortages and maldistributionincluding poor access, unmet needs, poorer health outcomes for 
patients, overworked health professionals and expensive strategies to address immediate workforce shortages by government - have long been recognised (HWA, 2012; Mason, 2013; Universities Australia, 2014).

To remedy health workforce shortages, rural and remote areas have in the past relied heavily on migration of international health professionals. While skilled migration is under review as an oversupply of Australian medicine and health professional graduates is predicted (Godwin et al., 2014; HWA, 2012; Universities Australia, 2014), maldistribution remains a key policy challenge (Mason, 2013). A trend towards specialisation and sub-specialisation within the health professions has also resulted in a shortage of 'generalists' capable of practice in areas of workforce need (Murray et al., 2012; Scott \& Joyce, 2014; United Nations, 2013).

There is now broad acknowledgement that a 'business as usual' approach to health workforce development in Australia is unsustainable (Mason, 2013; NHWPRC, 2010). Approaches going forward need to build on a history of significant health system and health workforce innovation targeted to the ongoing health disparities and health workforce challenges across Northern Australia.

\section{Innovation and Reform of Health Care and Health Workforce in Northern Australia}

Successive administrations at the federal, state and territory levels have sought to address the complexity of providing health care to those rural and remote populations most in need, but many have been unsuccessful. Although significant challenges remain, the lessons learned from past initiatives and current policy successes position Northern Australia as a leader in innovative health and health workforce policy to meet the needs of a diverse and dispersed population.

Service models and models of care to provide high-quality patient care in rural and remote areas are different from those in larger communities, and while rural and remote heterogeneity means that no single model of service can be applied, exemplars provide a basis for future development of service models (Mason, 2013; NHWPRC, 2010; Productivity Commission, 2005; Universities Australia, 2014). 
Recognising the benefits of local innovation and governance to meet local health needs, the National Health Reform Agreement of 2011 provided for the establishment of Local Hospital Networks (LHNs) with the aim of delivering better access to services, improved local accountability and transparency and greater responsiveness to local communities. Ten are located within Northern Australia (wholly or in part). ${ }^{3}$ Decentralised hospital and health service management within the LHNs is provided for by local governance arrangements so that the health services located in Northern Australia will be more responsive to local needs and challenges.

To meet health workforce challenges, HWA was established by the Council of Australian Governments through the 2008 National Partnership Agreement on Hospital and Health Workforce Reform. HWA's mandate was to deliver a national coordinated approach to create a health workforce able to meet the current and future health care needs of all communities. HWA developed a significant array of programs to address some of the challenges in health workforce development across Australia, including innovative rural and remote workforce reform strategies (Mason, 2013; NHWPRC, 2010; Universities Australia, 2014). HWA as a statutory authority has been abolished, but many of its functions and programs are continuing through consolidation within the Commonwealth Department of Health.

One of HWA's key programs, the Clinical Training Funding (CTF) program, provided significant and welcome investment that successfully increased clinical placement capacity across the health professions, including expanding opportunities across a range of non-traditional placement settings. However, an unforeseen consequence of the payment of fees to placement providers for the clinical training of health professional students was the creation of an expectation of continuing payment from universities for placements across the health disciplines at the HWA rate. While the CTF has been discontinued, the expectation of payment for clinical placements continues.

Currently, there is significant variation in the rate charged by clinical placement providers across health services, jurisdictions and discipline areas. This is a significant challenge facing the health and higher education sectors across Australia, and particularly for providers in rural and remote

3 These have evolved into various entities with Hospital and Health Services in Queensland, Health Districts in the Northern Territory and Health Networks in Western Australia. 
areas where there is a less established tradition of education, training and research; less investment and less infrastructure to support these activities; and high costs associated with providing clinical placements and student accommodation.

There is wide recognition of the vital role that Northern Australian universities working in partnership with health service providers play throughout Asia and the Indo-Pacific region as clinical education and training institutions (Universities Australia, 2014; United Nations, 2013). Further, the potential for collaborative initiatives between northern health services, universities and international partners is also emerging, such as Academic Health Centres (referred to as integrated health research centres in the 2013 McKeon Review) (Commonwealth of Australia, 2013) and institutions like the GNARTN and Cooperative Research Centre for Northern Australia (Australian Government, 2015). Future policy directions must address these trends and capitalise on the available opportunities to build tropical expertise and grow the knowledgeable, adaptable and appropriately skilled fit-for-purpose health workforce that the region needs.

The GNARTN was established in $2012^{4}$ and has worked to build and enhance clinical placement and health workforce capacity across Northern Australia. GNARTN is a partnership between the director generals of Western Australia, Queensland and the Northern Territory Health Departments and has demonstrated the benefits, including efficiency gains, of east-west collaboration between all parties involved in health professional training (governments, non-government organisations and higher education providers). Since 2013, GNARTN, through a shared investment and governance model, delivered a range of initiatives at a price point that allowed a higher return on the investment made by the individual jurisdiction.

The challenges presented by the determinants of health in Northern Australia have created the opportunity for it to become a national leader in development and delivery of significant health service and health workforce innovations that meet population health needs, including:

4 For information on GNARTN governance and scope see www.gnartn.org.au (site discontinued). 
- Building rural pipelines, or the continuum of training in rural or remote areas, in medicine (from recruitment to graduation, to junior doctor training, to employment as a junior doctor and on to vocational training in a medical speciality including general practice). Key recommendations of the Mason Review centre on the imperative to create coherent pathways for rural and regional education and training, particularly generalist medical training, with more appropriate resource allocation to nursing, midwifery, allied health and dentistry (Australian Government, 2015; Mason, 2013). The data on medical training at an undergraduate level, junior doctor level and vocational training level indicate that supporting rural and remote service providers and health professional trainees with accommodation, travel, supervision capacity and peer support while on rural and remote clinical placement leads to many health professionals returning to rural and remote areas following graduation (Sen Gupta et al., 2015). Supporting the articulation of rural training pipelines across the health professions is an important health workforce initiative and remains a critical area for further investment.

- Expanding scopes of practice for health practitioners. Rural and remote clinical practice in Australia already has established traditions of multidisciplinary team-based approaches to health care, including skill sharing and expanded scope of practice roles for nurse practitioners, midwives, practice nurses, enrolled nurses, remote area nurses, allied health professionals, rural pharmacists, Aboriginal and Torres Strait Islander health workers, rural paramedics and lay health care assistants. There is significant scope for expanded scopes of practice of other registered health professionals to address workforce shortages and help ensure that the evolving abilities of all members of the health care team can be fully applied.

- Smart use of technology, supported by the integrated telehealth system, point of care testing and 'tele-supervision' of students and trainees. The availability of broadband technology supported by effective models of care that utilise the existing rural and remote health workforce has the capacity to reduce cost of service while providing high-quality care to rural and remote patients. Western Australia and Queensland have already made significant advances in telehealth models of care. For example, Queensland has been piloting a telehealth supported model to deliver treatment and ongoing care to rural clients without them having to travel into the major urban 
centres. In Western Australia, the Western Australia Country Health Service has been effectively using videoconferencing to support nurses dealing with medical emergencies in small rural communities, thus providing immediate access to specialists who can support the rural practitioner in complex cases.

- Promoting rural and remote generalist specialists across all health professional groups, based on the model offered by rural generalist medicine, which is defined as the provision of a broad scope of medical care by a doctor in the rural context. Rural generalist medicine encompasses comprehensive primary, hospital and emergency care with a population health approach and within a multidisciplinary team, in contrast to medicine and medical training in major Australian cities, which has become increasingly sub-specialised and often shaped by income-earning opportunities, rather than by community needs. Rural generalism is well established in Queensland, with more recent adoption in the Northern Territory and other jurisdictions. A major initiative seeking to respond to the demand for generalist skills in other disciplines has been the development of the Allied Health Rural Generalist Pathway being undertaken in Queensland and rolled out across other states.

These areas of health and health workforce innovation and reform, within a cross-jurisdictional Northern Australian model, are outlined in Table 4.1.

As highlighted by the Mason Review, the current health reform era represents a shift away from acute care towards more coherent delivery of connected primary health care, with a focus on prevention and better management of chronic diseases and encouraging greater flexibility and productivity (Mason, 2013). This approach offers many benefits to health care in Northern Australia, and underscores the need for continuing investment in, and policy support for, key innovations and reforms that meet health care needs in rural and remote areas that are cognisant of demographic and epidemiological transitions. 
Table 4.1: Directions of health system and workforce innovation and reform in Northern Australia.

\begin{tabular}{|c|c|c|c|}
\hline \multicolumn{4}{|c|}{ Cross-jurisdictional Collaborative Model for Improved Health Outcomes } \\
\hline $\begin{array}{l}\text { Improve access to } \\
\text { health services }\end{array}$ & $\begin{array}{l}\text { Health professional } \\
\text { workforce } \\
\text { development }\end{array}$ & Telehealth & $\begin{array}{l}\text { Reformed } \\
\text { resourcing and } \\
\text { governance model }\end{array}$ \\
\hline $\begin{array}{l}\text { Fair, equitable and } \\
\text { universal access to } \\
\text { health services }\end{array}$ & $\begin{array}{l}\text { Address } \\
\text { maldistribution of } \\
\text { the health workforce } \\
\text { across Northern } \\
\text { Australia }\end{array}$ & $\begin{array}{l}\text { Enable greater } \\
\text { access and } \\
\text { equity to health } \\
\text { services }\end{array}$ & $\begin{array}{l}\text { Northern Australia } \\
\text { governance } \\
\text { mechanism to } \\
\text { support the adoption } \\
\text { of evidence-based } \\
\text { models across } \\
\text { jurisdictions }\end{array}$ \\
\hline $\begin{array}{l}\text { Smart use of } \\
\text { technology, including } \\
\text { telehealth, point of } \\
\text { care testing and } \\
\text { 'tele-supervision' of } \\
\text { students and trainees }\end{array}$ & $\begin{array}{l}\text { Appropriately educate } \\
\text { and train workforce } \\
\text { for rural/remote } \\
\text { practice }\end{array}$ & $\begin{array}{l}\text { Reduce } \\
\text { costs and } \\
\text { inconvenience } \\
\text { associated } \\
\text { with accessing } \\
\text { specialist health } \\
\text { services }\end{array}$ & $\begin{array}{l}\text { Legislative and } \\
\text { policy alignment } \\
\text { (e.g. harmonised } \\
\text { drugs and poisons } \\
\text { regulations and } \\
\text { clinical guidelines) }\end{array}$ \\
\hline $\begin{array}{l}\text { Regional partnerships } \\
\text { between government } \\
\text { and non-government } \\
\text { organisations to } \\
\text { support continuum } \\
\text { of care }\end{array}$ & $\begin{array}{l}\text { Share and mobilise } \\
\text { workforce across } \\
\text { jurisdictions }\end{array}$ & $\begin{array}{l}\text { Improve access } \\
\text { to quality, locally } \\
\text { available clinical } \\
\text { services }\end{array}$ & $\begin{array}{l}\text { Co-investment model } \\
\text { to reduce cost burden } \\
\text { and risk, achieving } \\
\text { greater access } \\
\text { through greater equity } \\
\text { in resourcing }\end{array}$ \\
\hline $\begin{array}{l}\text { Shared specialist } \\
\text { health workforce in } \\
\text { Northern Australia }\end{array}$ & $\begin{array}{l}\text { Share recruitment } \\
\text { models }\end{array}$ & $\begin{array}{l}\text { Enable access } \\
\text { to continuing } \\
\text { education and } \\
\text { professional } \\
\text { development } \\
\text { for health } \\
\text { professionals }\end{array}$ & $\begin{array}{l}\text { Integrated research, } \\
\text { education and health } \\
\text { care via an Academic } \\
\text { Health Centre } \\
\text { combining research, } \\
\text { higher education and } \\
\text { health sectors }\end{array}$ \\
\hline $\begin{array}{l}\text { Expand roles of } \\
\text { practice for health } \\
\text { professionals } \\
\text { (generalist) }\end{array}$ & $\begin{array}{l}\text { Increase access to } \\
\text { specialist workforce } \\
\text { across jurisdictions }\end{array}$ & $\begin{array}{l}\text { Enable } \\
\text { networking and } \\
\text { collaboration } \\
\text { to support } \\
\text { workforce } \\
\text { retention }\end{array}$ & $\begin{array}{l}\text { Cost-effective service } \\
\text { models based on } \\
\text { collaborative service } \\
\text { planning }\end{array}$ \\
\hline $\begin{array}{l}\text { Share collaborative } \\
\text { health service/ } \\
\text { population health } \\
\text { planning models }\end{array}$ & $\begin{array}{l}\text { Strengthen links } \\
\text { between the health } \\
\text { system and the } \\
\text { higher education } \\
\text { sector }\end{array}$ & $\begin{array}{l}\text { Develop and } \\
\text { deliver telehealth } \\
\text { services across } \\
\text { jurisdictions and } \\
\text { geographical } \\
\text { boundaries }\end{array}$ & $\begin{array}{l}\text { Models recognising } \\
\text { the cost of provision } \\
\text { of services in } \\
\text { rural and remote } \\
\text { environments }\end{array}$ \\
\hline
\end{tabular}




\begin{tabular}{|c|c|c|c|}
\hline \multicolumn{4}{|c|}{ Cross-jurisdictional Collaborative Model for Improved Health Outcomes } \\
\hline $\begin{array}{l}\text { Improve access to } \\
\text { health services }\end{array}$ & $\begin{array}{l}\text { Health professional } \\
\text { workforce } \\
\text { development }\end{array}$ & Telehealth & $\begin{array}{l}\text { Reformed } \\
\text { resourcing and } \\
\text { governance model }\end{array}$ \\
\hline $\begin{array}{l}\text { Strengthen public } \\
\text { health as a preventive } \\
\text { mechanism }\end{array}$ & $\begin{array}{l}\text { Enhance Aboriginal } \\
\text { and Torres Strait } \\
\text { Islander workforce } \\
\text { development } \\
\text { opportunities } \\
\text { including health } \\
\text { practitioner workforce }\end{array}$ & $\begin{array}{l}\text { Achieve service } \\
\text { delivery that } \\
\text { reduces current } \\
\text { inequity in } \\
\text { access and } \\
\text { associated poor } \\
\text { health outcomes }\end{array}$ & $\begin{array}{l}\text { Innovative service and } \\
\text { workforce models }\end{array}$ \\
\hline $\begin{array}{l}\text { Strengthen } \\
\text { Indigenous and } \\
\text { rural and remote } \\
\text { primary health care } \\
\text { infrastructure }\end{array}$ & $\begin{array}{l}\text { Technology-enabled } \\
\text { solutions to address } \\
\text { the significant } \\
\text { maldistribution of } \\
\text { the health workforce } \\
\text { across rural and } \\
\text { remote Northern } \\
\text { Australia }\end{array}$ & & \\
\hline
\end{tabular}

Source: Adapted from Davis and Vernon (2014).

\section{A Healthy Population Leading Australia in the Asia-Pacific Century}

Northern Australia continues to establish itself as a leader in innovative health and health workforce policy to meet the needs of a diverse and dispersed population. Domestically, a healthy population means a healthy and productive workforce available to industry and business to underpin economic development. Looking further afield, Northern Australia is well placed to develop these areas of expertise as an export commodity. Northern Australia has established significant expertise in responding to disasters, managing tropical diseases and developing strategies to prevent and managing chronic diseases (Murray et al., 2012; United Nations, 2013). Combined with significant experience in rural and remote health workforce development and health system innovations-evidenced by the international demand for Australian-trained remote area nurses by international aid agencies for their skill, knowledge diversity and ability to work in resource-poor environments-Northern Australia also has a lot to offer other nations striving to achieve the goal of universal health coverage (United Nations, 2013). 
Engagement with Asia and the Indo-Pacific region in education and health care has enormous strategic significance. Efficient and effective health systems with equitable foundations underpin sustainable development, security and economic growth, thus benefiting regional stability (Australian Government, 2015; Commonwealth of Australia, 2012; Hill, 2013; Murray et al., 2012; State of the Topics, 2014, 2017; United Nations, 2013). Additionally, Australia's reputation as a quality provider of health care and health professional education within a region with a growing middle class offers significant market opportunities in international education, health care and medical tourism.

The contribution of the higher education sector to the health and economic positioning of the region is significant. Universities in Northern Australia not only train the future health professionals of the region to meet health workforce needs, but strengthen the economy and build vital diplomatic links internationally. Currently, international education is Australia's largest export earner after resources and Australia's fourth largest export industry, earning around $\mathrm{A} \$ 15$ billion annual (Australian Government, 2015; Joint Select Committee on Northern Australia, 2014). Universities and research institutes are also driving research into emerging and reemerging tropical infectious diseases and new models of care and service delivery for chronic disease, offering the potential for huge economic, social and health benefits to the local region, nation and neighbouring countries.

Ongoing investment in health services strengthening, health workforce development, and health and medical research will ensure that Northern Australia is recognised as a global leader in rural, remote and tropical health care and workforce innovation.

There are significant health and economic benefits to developing Northern Australia. To maximise these benefits, there is a need for sustained bipartisan political commitment to establish a robust Northern Australia east-west dialogue. This dialogue should be supported by a governance mechanism that enables collaboration between the Commonwealth and Western Australian, Northern Territory and Queensland governments. 


\section{Key Summary Points}

- A healthy population means a healthy and productive workforce available to industry and business to underpin economic development.

- Establishing an overarching east-west governance arrangement, supported by a series of alliances and focused on the critical issues identified in Table 4.1, will enhance the region's capacity to grow and develop, with significant benefits for Australia and its near neighbours.

- Health in Northern Australia reflects a combination of unique geographic and demographic factors, including poorer health status (with Northern Australia representing approximately one-third of Australia's outer regional and remote population), and geographic maldistribution of health professionals, meaning shortages in rural and remote areas.

- In health workforce development, ensuring availability and affordability of clinical training remains a significant challenge, particularly for providers in rural and remote areas where there is a less established tradition of education, training and research, less investment and less infrastructure to support these activities as well as higher costs associated providing clinical placements.

- Universities play an essential role in training future health professionals of the region to meet health workforce needs, strengthening the economy and building vital diplomatic links internationally.

- Northern Australia is leading the country in developing and delivering a number of health service and health workforce innovations to meet health needs in the region, including building rural pipelines in medicine, expanding scopes of practice for health practitioners, smart use of technology including telehealth, and promoting rural and remote generalist specialists across all health professional groups.

- Northern Australia is well placed to develop its health service and health workforce innovation expertise as an export, particularly to Asia and the Indo-Pacific region.

On the basis of the research evidence and the opportunities discussed in this chapter, the following recommendations are made for future policy and practices. Implementation of these recommendations enables strategic investment in the opportunities to build the capacity of the region to develop a healthy and productive population in Northern Australia. 
Recommendation 1: Establish and strengthen inter-sectoral and crossjurisdictional partnerships to provide accessible, effective and efficient health services across Northern Australia through:

- east-west governance arrangements that strengthen service delivery and collaboration between the not-for-profit sectors, private enterprise and state governments

- regional partnerships between government and non-government organisations that:

- facilitate collaborative health services planning and modelling

- provide an integrated and cooperative continuum of care across services and the region that supports the patient journey

- effectively address inequities in access to services

- collaboratively and inclusively address critical challenges to the health of the populations.

Recommendation 2: Employ strategies that develop an appropriate health workforce for Northern Australia and the region by:

- creating and further developing education and clinical training hubs that:

- work cooperatively and collaboratively with health service providers across Northern Australia to grow an appropriate regional, rural and remote health workforce

- provide affordable, quality clinical experiences for students

- enable the export of health professional education and clinical training to the Asia-Pacific region

- maximise opportunities to implement and evaluate innovative workforce models such as Indigenous health practitioners, nurse practitioners and tropical/rural training pathways

- provide the expertise to develop rural generalist practitioners with the expanded scope of practice required in this context

- provide continuing education and professional development for health professionals

- leverage existing Northern Australia capability around disaster preparedness and management. 
- east-west arrangements that transcend jurisdictional barriers and enable;

- implementation of strategies to address the maldistribution of the health workforce

- shared specialist health workforce in Northern Australia

- shared recruitment and retention strategies

- telehealth service delivery that provide access to networks, support and training without geographical barriers.

Recommendation 3: Reform resourcing and governance models across jurisdictions and sectors in Northern Australia to:

- align legislation and harmonise policies (e.g. around credentialing, scope of practice, drugs and poisons, and clinical guidelines)

- enable co-investment into training, resources and technology-assisted solutions that enable equitable access with a reduced cost burden

- developing and evaluating innovative service models and providing cost-effective service delivery

- integrate research, education and health care through formal Northern Australia governance structures to build capability and export regional expertise

- support and share evidence-based workforce models

- strengthen Indigenous and rural and remote primary health care infrastructure.

Prioritisation of, and ongoing investment in, health services strengthening, health workforce development, and health and medical research in Northern Australia will ensure the region is recognised as a global leader in rural, remote and tropical health care and workforce innovation. This needs to be underpinned by an overarching governance arrangement focused on the critical health and health workforce issues in the region. With sustained political commitment to Northern Australia, this tropical region has the potential and capacity to be the leading provider of innovative health service models, public health research and health professional education. 


\section{Postscript}

This chapter was originally written in late 2016 . With proposed publication in 2021, there is a unique opportunity to reflect on progress towards addressing the challenges and leveraging the opportunities highlighted in this chapter.

Every year since 2016, the Annual Statement on Developing Northern Australia has been delivered by the current minister responsible for Northern Australia, and it would appear in the period between 2016 and 2021 that significant progress has been achieved in laying the foundations to support investment and leveraging of opportunities in Northern Australia.

The question remains in the minds of the authors as to whether the northern development agenda has delivered better outcomes for the communities of Northern Australia and, in particular, whether the recommendations identified in this chapter have been realised.

The establishment of the Cooperative Research Centre for Developing Northern Australia, a key recommendation from the 2015 White Paper, has served to support and invest in research, commercialisation and addressing supply chain issues with respect to Northern Australia health service delivery (including identifying new models and approaches, early detection, health-seeking behaviour and mental health). There appears to have been very little action in relation to the recommendations drafted in 2016, and in 2020 the CRCNA published a Northern Australia health service delivery situational analysis (Edelman et al., 2020). In this 2020 report the challenges identified and the recommendation to develop a systemic approach to enable collaboration and informationsharing are consistent with recommendations from 2016-namely, the lack of structural mechanisms to bring together key stakeholders to drive a strategic agenda remains an impediment to success. Pre-existing governance structures such as the GNARTN (which was funded by the Commonwealth Department of Health) were disestablished in June 2017, and the lack of systematic coordination, collaboration and co-investment in innovation and information-sharing between primary care networks, local health networks and LHNs and those universities and institutions with expertise in this area further exacerbate the fragmentation of effort and limits investment. 
The Ministers Forum on Northern Australia, in combination with the Senior Officers forums supported by the Office of Northern Australia, does continue to provide a mechanism to enable strategic dialogue; however, evidence of the impact of this high-level collaboration is limited. While high-level dialogue is important, the ability to drive innovation, reduce duplication and improve outcomes through effective operational collaboration between states on shared issues remains limited without appropriate and strategic governance arrangements providing a foundation from which to invest.

Ongoing and regular changes in the funding and policy environment to increase health workforce clinical training capacity has had mixed outcomes. The ongoing investment in University Department of Rural Health (UDRH) and establishment of a UDRH in northern Western Australia is a positive outcome that will increase clinical training capacity in Northern Australia. All parties committed to supporting a regional homegrown medical, nursing, allied health and Indigenous health practitioner workforce to service local communities find their efforts confounded by the lack of a consistent and harmonised approach across Northern Australia. The diversity of positions taken by peak health professional bodies limits access and supervision in the provision of clinical placements. There is also legislative and regulatory discord between the three northern jurisdictions. The ongoing prioritisation to fund medical training over other health profession groups is also leading to a medically focused model, as opposed to a multidisciplinary teambased approach, which is more cost-effective and has better health outcomes, especially within Indigenous communities. Significant changes in policy have resulted in the loss of clinical training capacity, which had enabled universities to fund clinical placement opportunities in regional, rural and remote communities. There is evidence that providing wellsupported clinical placement opportunities in regional, rural and remote areas increases the likelihood of students returning to a rural area and transitioning successfully into rural practice following graduation.

In 2021, workforce maldistribution in Northern Australia remains a key challenge, and a key recommendation of this chapter in 2016 was to develop a training system that leverages the existing training infrastructure of the Northern Territory, Queensland and Western Australia and, via collaborative partnerships, develop integrated training pathways that 
leverage this infrastructure and clinical training capacity so that students could systematically access this capacity across the north to enable an east-west training pipeline.

A significant gamechanger identified in Recommendation 3 of this chapter (in 2016) was a recommendation to work with the northern jurisdictions to harmonise legislation and policies to facilitate the health professional workforce to be more mobile between the three jurisdictions. Currently, there are a number of limitations and variances between the scope of practice of various health professionals in the north. The more these barriers to practice can be reduced, the more mobile health professional can be. Increasing mobility by minimising variances between the northern regions will contribute to addressing health workforce maldistribution, an area of work that has the potential to resolve a number of significant barriers to workforce mobility in Northern Australia, and could be within the remit of the CRCNA.

While the Northern Australia development agenda has created opportunities for Northern Australian communities, to date in 2021 outcomes in addressing workforce maldistribution in Northern Australia remain limited. The loss of any effective mechanism to drive collaboration and co-investment in innovative and systemic solutions across all three jurisdictions will continue independently of each other and not achieve the collective benefit from collaboration that the Northern Australia development foreshadowed.

The arrival of COVID-19 in 2020 reinforced Australia's position as being a centre of excellence in health service delivery and models of care, tropical public health and innovations in health professional training. However, our capacity to get this to market remains limited and marginal in the context of international market dynamics. Through effective and strategic collaboration between health system managers, universities and legislators, Northern Australia could address these issues and generate significant opportunities as a centre for expertise and education for the international market.

\section{References}

Australian Bureau of Statistics (ABS). (2017). Regional population growth, Australia, 2016. (No. 3218.0). Canberra, ACT: ABS. 
Australian Bureau of Statistics (ABS). (2018a). Education and work Australia, May 2018 (No. 6227.0). Canberra, ACT: ABS.

Australian Bureau of Statistics (ABS). (2018b). Estimates of Aboriginal and Torres Strait Islander Australians, June 2016. (No. 3238.0.55.001. Canberra, ACT: ABS.

Australian Government. (2015). Our north, our future: White paper on developing Northern Australia. Retrieved from www.industry.gov.au/data-and-publications/ our-north-our-future-white-paper-on-developing-northern-australia

Australian Institute of Health and Welfare (AIHW). (2013). Nursing and midwifery workforce 2012 (National Health Workforce Series No. 6, Cat. No. HWL 52). Canberra, ACT: AIHW.

Australian Institute of Health and Welfare (AIHW). (2018). Australia's health 2018 (Australia's health series no. 16, Cat. No. AUS 221). Canberra, ACT: AIHW.

Australian Medical Workforce Advisory Committee. (1998). Medical workforce supply and demand in Australia: A discussion paper (AIHW Cat. No. HWL 12). Sydney, NSW: AMWAC.

Commonwealth of Australia. (2012). Australia in the Asian century. Canberra, ACT: Commonwealth of Australia.

Commonwealth of Australia. (2013). Strategic review of health and medical research. Canberra, ACT: Department of Health and Ageing.

Davis, S. \& Vernon, M. (2014). Greater Northern Australia Regional Training Network submission to the Joint Select Committee on Northern Australia. GNARTN.

Department of Jobs and Small Business. (2018). ABS labour force regions- $A A 4$ data. Retrieved from lmip.gov.au/maps.aspx\#layer=LabourForceRegions

Edelman, A., Grundy, J., Moodley, N., Larkins, S., Topp, S.M., Atkinson, D., Patel, B., Strivens, E. \& Whittaker M. (2020). Northern Australia health service delivery situational analysis. CRCNA. Retrieved from crcna.com.au/ resources/publications/northern-australia-health-service-delivery-situationalanalysis

Edelman, A., Taylor, J., Ovseiko, P. V. \& Topp, S. M. (2018). “'Academic” is a dirty word': Intended impact pathways of an emerging academic health centre in tropical regional Australia. International Journal of Health Planning and Management, 34(1), e661-e678. doi.org/10.1002/hpm.2681 
Godwin, D. M., Hoang, H., Crocombe, L. A. \& Bell, E. (2014). Dental practitioner rural work movements: A systematic review. Rural and Remote Health, 14(3). Retrieved from www.rrh.org.au/publishedarticles/article_print_2825.pdf

Health Workforce Australia (HWA). (2012). Health workforce Australia, 2012. A summary of health workforce 2025-volumes 1 to 3. Adelaide, SA: HWA.

Health Workforce Australia (HWA). (2013). National rural and remote workforce innovation and reform strategy. Adelaide, SA: HWA.

Hill, C. (2013). Australia in the 'Indo-Pacific' century: Rewards, risks, relationships. In D. Heriot (Ed.), Parliamentary library briefing book-44th Parliament (pp. 144-146). Canberra, ACT: Australian Government.

Humphreys, J., Wakerman, J., Wells, R., Kuipers, P., Jones, J. \& Entwistle, P. A. (2006). Systematic review of primary health care delivery models in rural and remote Australia 1993-2006. Canberra, ACT: Australian Primary Health Care Research Institute.

Insight Economics. (2012). Review of dental workforce supply to 2020. Melbourne, Vic.: Australian Dental Association. Retrieved from hdl.voced. edu.au/10707/346119

Joint Select Committee on Northern Australia. (2014). Inquiry into the development of Northern Australia - interim report. Canberra, ACT: Parliament of the Commonwealth of Australia.

Liberal Party of Australia. (2013). The Coalition's 2030 vision for developing Northern Australia. Retrieved from parlinfo.aph.gov.au/parlInfo/search/ display/display.w3p;query=Id\%3A\%22library\%2Fpartypol\%2F2550511 $\% 22 ;$ src $1=$ sm 1

Mason, J. (2013). Review of Australian Government health workforce programs. Canberra, ACT: Department of Health.

Minister for Resources and Northern Australia. (2018). Northern Australia statement. Retrieved from www.minister.industry.gov.au/ministers/canavan/ speeches/2018-annual-statement-developing-northern-australia

Murray, K. A., Skerratt, L. F., Speare, R., Ritchie, S., Smout, F., Hedlefs, R. \& Lee, J. (2012). Cooling off health security hot spots: Getting on top of it down under. Environment International, 48, 56-64.

National Health Workforce Planning and Research Collaboration (NHWPRC). (2010). Refining the national workforce planning model. Final report. Adelaide, SA: HWA. 
Productivity Commission. (2005). Australia's health workforce. Canberra, ACT: Productivity Commission.

Scott, A. \& Joyce, C. M. (2014). The future of medical careers. Medical Journal of Australia, 201(2), 82-83.

Sen Gupta, T., Woolley, T., Murray, R., Hays, R. \& McCloskey, T. (2015). Positive impacts on rural and regional workforce from the first seven cohorts of James Cook University medical graduates. Rural and Remote Health, 14(1), 1-13. Retrieved from www.rrh.org.au/articles/showarticlenew.asp?ArticleID=2657

State of the Tropics. (2014). State of the tropics report. Cairns, Qld: James Cook University. Retrieved from www.jcu.edu.au/state-of-the-tropics/publications/ 2014-state-of-the-tropics-report

State of the Tropics. (2017). 2017 State of the Tropics Report: Sustainable infrastructure in the tropics. Townsville, Qld: James Cook University. Retrieved from www.jcu.edu.au/state-of-the-tropics/publications/2017-state-of-thetropics-report

United Nations. (2013). Universal health coverage at the center of sustainable development: Contributions of sciences, technology and innovations to health systems strengthening. Retrieved from www.un.org/en/ecosoc/julyhls/pdf13/ concept_paper-uhc_during_ecosoc_amr.pdf

Universities Australia. (2014). Universities Australia pre-budget submission 2014 15. Universities Australia.

Wakerman, J. (2004). Defining remote health. Australian Journal of Rural Health, 12(5), 210-214. doi.org/10.1111/j.1440-1854.2004.00607.x

World Health Organization (WHO). (2016). 'Travel and Health'. Retrieved from www.who.int/trade/en/ 
This text is taken from Leading from the North: Rethinking Northern Australia Development, edited by Ruth Wallace, Sharon Harwood, Rolf Gerritsen, Bruce Prideaux, Tom Brewer, Linda Rosenman and Allan Dale, published 2021 by ANU Press, The Australian National University, Canberra, Australia.

doi.org/10.22459/LN.2021.04 